The Bible Translator 2, no. 3 (1951):

131-132 


\section{A Caution on Greek Connectives}

by

\section{William John Samarin}

It is unfortunate that many translators and students of the Bible have not fully understood the use of Greek connectives. Some have evidently thought that because Greek connectives can apparently be easily translated into English, the English words are equivalent in use as well as meaning. This situation is further complicated by the fact that a great deal of translation is done directly from the Authorized Version, which, unfortunately, has often rendered the numerous Greek connectives more or less literally.

\section{The Conjunction "And"}

Even a small word such as a connective may affect some important point of doctrine. Note, for example, how some people understand the use of the connective "and" in Matthew 28:19. It is felt that because the word "and" is repeated twice, a distinction exists between this phrase and another possibility, namely, "the name of the Father, Son, and Holy Spirit". English examples are used to implement this contrast, for it is argued that the phrase "a can of blue, green, and white paint" is different from "a can of blue, and of green, and of white paint". On the basis of this kind of comparison some maintain a particular mode of baptism. Although there may be sufficient grounds for such a practice, it cannot be based on such syntactical comparisons.

One must neither try to set up one and only one English meaning for each one of the Greek connectives nor equate their uses with specific English words. They have meanings, but these must be studied in the light of the Greek, not English, syntax. It would not only be terribly difficult but wrong, to attempt to "squeeze out" an English significance from each word. The Gospel of Mark, for example, has a number of distinct uses of kai, and this connective occurs very frequently. Another example is the sixth chapter of Revelation. In the A.V. sixteen of the seventeen verses begin with "and". The seventeenth verse begins with "for", another connective. Altogether in this chapter there are sixty-two occurrences of the word "and", which means that every kai has been translated by the English "and". However, the two are not equivalent. Note that in the R.S.V. (1946) only five verses begin with "and".

The student and translator of the Bible is cautioned as to the translation and interpretation of the use of Greek connectives. The translator must first study the syntax of the recipient language to determine how it uses whatever connectives it may have. For example, the kai of Greek seems to differ greatly from the Navaho equivalent. In this language, as $\mathrm{Dr}$ Nida has pointed out, "and" may only. stand between two different items. 1

1"The Most Common Errors in Transllating", The Bible Translator, 1:54. 


\section{1 wo Lautions}

There are two reasons why one must take precautions:

1. A strictly literal translation may be cumbersome and laborious, if it is understandable at all. This is clearly seen in the A.V., where reading is made difficult by a syntax which is awkward for the English reader. With a great deal of practice, one eventually learns to overlook the unusual clauses and too frequent use of connectives. However, many people have been discouraged from reading the Word of God by such difficulties.

2. In many cases there may be actual error in interpretation as a result of literal renderings of connectives. The possibility of error arises. as was suggested above, when undue stress is laid on the use of "and". Because that word was translated into a construction formally similar to one found in English, it was made to teach something that may not have been meant at all. However, many similar examples could easily be cited, e.g. Acts $1: 8 ; 2$ Cor. $13: 14 ; 2$ Tim. 1:7; Rev. 1:4, 9, 11 .

It is not the purpose of this article to present an analysis of the use of Greek connectives nor of English equivalents. A discussion of the Greek words will be found in any good grammar.

\section{The Problem of Equivalence}

Nevertheless, just a few words may be given as an introduction to the reader's own study of the subject. Greek has been called a language of "hooks and eyes". By this it is meant that phrases and clauses are almost always joined in some way by the use of connectives. So frequent is their occurrence that their absence is to be noted. (See 1 Cor. 13:13: 2 Cor. $11: 26$; Eph. 6:12, et al.) Often a point is emphasized by their absence rather thans their presence. The reader of the Greek New Testament will find it valuable to ask himself on occasion, "Why is the connective omitted here?" rather than simply, "Why is the connective used here?" This practice is somewhat the reverse from that in English. One does not prick up his ears when he hears that "the doctor, minister, and mother walked into the room", but when he hears that "the doctor and the minister, and the mother walked into the room" he reacts to the nonnormal usage. These two sentences differ, of course, in more ways than one. The chief difference is usually not in the presence or absence of the first "and" but in the distinctive intonation of the sentence. (The italicized words indicate a significant intonational emphasis.)

In short, it must be said that the student of the Bible should be careful not to equate literally in a word-for-word system the lexical and syntactic elements of Greek with that of English or any other language. Only after the translator studies carefully the syntax of the donor and recipient languages can he set up the various types of correspondences, depending on the different contexts. 